\title{
Economic Analysis of Rice Transport Machine Replacing Manual Operation
}

\author{
M.Y.Zhang \& J.Y.Wei \& D.D.Bai \& X.T.Wang \\ School of Management, Tianjin University of Technology, Tianjin, China
}

\begin{abstract}
Rice production mechanization has important practical significance to ensure food security, improve the production efficiency, and reduce labor cost. This article is based on field investigation data of transfer machine running situation. By the statistical method, it studies the transfer machine and man-machine efficiency, investment payback period and cost, and the influence of transport machine on the field of soil compaction. The results show that the rice transport machine, compared with manual operation, can save labor cost 7 to 9 times, farmers bought transport machine only spend two years recovering the investment and profit. After rice transport machine achieves batch production, it can fill the gaps in rice production. It also helps to realize the fully mechanization in rice production.
\end{abstract}

KEYWORD: rice transport machine; man-machine efficiency; economic analysis

\section{INTRODUCTION}

Rice is the main food crops in China, It has some characteristics. They include many production links, high labor intensity, much labor capacity [1]. As a result, the ministry of agriculture agricultural mechanization management made the development plan of national rice production mechanization decade (2006-2015). After decades of continuous development, the comprehensive mechanized degree in 2012 has reached to $40 \%$, some provinces of mechanization have been close to $90 \%$ [2]. Rice farming mechanization degree has greatly increased, but a complete set of rice harvest technology development is not sufficient to meet the actual needs of agricultural production in our country.

\section{7S-20 RICE TRANSPORT MACHINE PERFORMANCE INDEXES AND PRODUCT FEATURES}

\subsection{Performance indexes}

The machine type of $7 \mathrm{~s}-20$ rice transport machine is knapsack. Its hydraulic system adopts double pumps and double motor configurations. Its appearance size is 3.1 meters long, 1.6 meters wide, 1.83 meters high. Its weight is 2 tons and its maximum load is 1.5 tons. Its forward velocity is divided into two gear, one $0-2.5 \mathrm{~km} / \mathrm{hour}$, the other 0 to $5 \mathrm{~km} / \mathrm{h}$.

\subsection{Product characteristics analysis}

To ensure product performance and reliability, it adopts the mature mechanism design of four-wheel area and all of its fittings manufacturers are brand enterprises at home and abroad. On this basis, in order to improve chain walking in the muddy rice land and wider applicability, it targeted to develop a new frame body structure, strengthen the frame rigid body, and improve the clearance between the frame body and crawler.

Electrical system design uses the security protection measures. Parking brake operating mode, the engine can be started, otherwise, it can't. So it can ensure to avoid dangerous operation and safety accidents. Instrument panel is combined type with lights.

Vehicle drive system adopts a hydraulic design concept. Open system, in contrast to closed system, guarantee the quality of premise better, more reliable and reduce the cost more effectively. In the process of operation and maintenance, the operator can better qualify.

\section{THE MAN-MACHINE EFFICIENCY CONTRAST}

\subsection{Handling efficiency analysis of rice farmers}

In order to test the ability of handling equipment, the author in the autumn of 2013 went to the Ninghe County for randomly collecting 15 rice farmers in 
the fields handling capacity a day, which is the handling of rice sack. Through on-the-spot investigation, therefore, we get a random sample of 15 farmland data. The data is shown in table 1 .

After the second column of table 1 is statistically analysis, which is each rice farmers every day carrying rice bags, the output:

$$
\bar{N}=58.6
$$

$\bar{N}$ is the average number of handling for rice farmers every day.

Table 1 reduction of Manual handling rice data

\begin{tabular}{|c|c|c|c|c|c|}
\hline $\begin{array}{l}\text { Test } \\
\text { number }\end{array}$ & $\begin{array}{l}\text { Each rice farmers every } \\
\text { day carries rice sack(sack) }\end{array}$ & $\begin{array}{l}\text { The weight of each } \\
\text { bag of rice }(\mathrm{kg})\end{array}$ & $\begin{array}{l}\text { Each rice farmers harves The number of ba } \\
\text { number of mu(mu) }\end{array}$ & $\begin{array}{l}\text { The number of bag per acre } \\
\text { in each rice field }\end{array}$ \\
\hline$n$ & $N$ & $X$ & $S$ & $m$ & $m^{\prime}$ \\
\hline 1 & 60 & 39.2 & 2 & 35 & 18 \\
\hline 2 & 61 & 40.5 & 1.5 & 24.5 & 14 \\
\hline 3 & 59 & 38.9 & 3 & 17 & 17 \\
\hline 4 & 55 & 41.2 & 1 & 49 & 19 \\
\hline 5 & 53 & 40.1 & 2.6 & 115.5 & 19 \\
\hline 6 & 62 & 39.7 & 6 & 127.7 & 20 \\
\hline 7 & 64 & 40 & 6.5 & 140 & 18 \\
\hline 8 & 58 & 41.7 & 8 & 63 & 16 \\
\hline 9 & 57 & 42 & 4 & 47.25 & 16 \\
\hline 10 & 55 & 40.3 & 3 & 87.5 & 18 \\
\hline 11 & 56 & 39.8 & 2 & 47 & 16 \\
\hline 12 & 63 & 40 & 5 & 70 & 18 \\
\hline 13 & 61 & 39 & 3 & 27.5 & \\
\hline 14 & 65 & 41.6 & 4 & & 18 \\
\hline 15 & 50 & 38.5 & 1.5 & & 18 \\
\hline
\end{tabular}

In order to measure the artificial handling workload, we introduce the efficiency formula (unit: $\mathrm{mu})$ :

$$
\eta=\frac{N \cdot X}{Y}
$$

$\eta$ is each of the rice farmers work efficiency; $X$ is the weight of each bag of rice; $Y$ is the rice yield per acre; $N$ is the total number of transporting bags by a rice farmer per day.

Based on the third column in table 1, after statistical analyzed, the result is:

$$
\bar{X}=40.17
$$

$\bar{X}$ is all the average weight of rice.

On the basis of the fourth column in table 1 and the fifth column data, we can get the sack of rice per mu.

namely the sixth column in table 1 . Among them, $S$ is the number of mu rice every farmers harvest; $m$ is the number of each paddy rice in the bag, $m^{\prime}$ is the number of paddy rice bags for every rice farmers after the integer number per acre. After statistical analysis, the result is:

$$
\bar{m}^{\prime}=17.4
$$

$\vec{m}$ is the average number of rice sack per mu for every rice farmers.

Through the analysis of the above two kinds of data, the result is:

$$
Y=\bar{X} \cdot \bar{m}^{\prime}=40.17 \times 17.4=698.96 \mathrm{~kg}
$$

$Y$ is paddy rice yield per acre.

So we can get the result:

$$
\bar{\eta}=\frac{58.6 \times 40.13}{698.96}=3.36
$$

$\bar{\eta}$ is the average number of paddy fields per mu for a rice farmer every day;

\subsection{Efficiency analysis of transfer machine}

In order to determine the efficiency of rice harvester, through on-the-spot investigation we records the daily workload in ten working days. The data is in table 2 . 
Table 2 the daily workload of rice harvester (unit: $\mathrm{mu}$ )

\begin{tabular}{|c|c|c|c|c|c|c|c|c|c|c|}
\hline$t$ & 1 & 2 & 3 & 4 & 5 & 6 & 7 & 8 & 9 & 10 \\
\hline$Z$ & 145 & 140 & 138 & 120 & 150 & 128 & 130 & 136 & 133 & 140 \\
\hline
\end{tabular}

From the above data it can be obtained that harvest efficiency of a rice harvester $Z=120-150 \quad \mathrm{mu}, \quad$ average harvest efficiency $\bar{Z}=136 \mathrm{mu}$.

\subsection{Efficiency of transfer machine and rice farmers}

Table 3 efficiency of transfer machine and rice farmers

\begin{tabular}{|l|c|c|}
\hline & $\begin{array}{l}\text { Transfer } \\
\text { machine }\end{array}$ & $\begin{array}{l}\text { Rice } \\
\text { farmers }\end{array}$ \\
\hline $\begin{array}{l}\text { The number of handing every } \\
\text { day (average) }\end{array}$ & 136 & 3.36 \\
\hline $\begin{array}{l}\text { The number of man matching } \\
\text { harvester(average) }\end{array}$ & 6 & 40 \\
\hline
\end{tabular}

Rice transportation machine, therefore, can easily cope with the rice harvester harvest, avoiding the problem that stacking time in the field is too long. And the efficiency of rice transport machine is far greater than the efficiency of artificial; it is artificial 36-45 times. In addition to this, it greatly reduces the number of porters and saves manpower 7 to 9 times.

\section{THE PAYBACK PERIOD AND COST ANALYSIS}

Economic returns are another indicator of practical significance for farm machinery.

According to the formula of profit:

$$
L=P-C
$$

$P$ is the total revenue; $C$ is the total cost.

Hence, buyers in the profits of a harvest period:

$$
L^{\prime}=t \cdot b \cdot S_{\text {min }}-t \cdot l_{\text {max }} \cdot c-t \cdot m_{\max } \cdot r_{\max }-x
$$

Transfer machine, s oil consumption $l=20-25$ liters per day, the current diesel price $c=7.18$ yuan/liter; The human cost $r=100-150$ yuan/day; land income per acre of transfer machine $b=30-35$ yuan/mu; China's average harvest time $t=20$ days; Other costs (transportation cost, maintenance costs, taxes, etc.) $x=25000_{\text {yuan. }} S_{\text {min }}$ is the minimum workload of transport machine every day; ${ }_{\text {max }}$ is the largest fuel consumption of transfer machine every day; ${ }^{m}{ }_{\max }$ is the largest number of man equipped with the transport machine; ${ }^{r_{\max }}$ Is the biggest human cost.

The calculation can be: $L^{\prime}=25410$ yuan.

Hence, the payback period:

$$
T=\frac{P \cdot(1-y)}{L^{\prime}}=1.5
$$

The price of $7 \mathrm{~S}-20$ rice transport machine $P=53000$ yuan, state subsidies $y=30 \%$.

Thus, cost recovery period of $7 \mathrm{~s}-20$ rice transport machine is about 2years, and in the second year it can be profitable.

\section{THE INFLUENCE OF TRANSPORT MACHINE ON THE FIELD OF SOIL CONPACTION}

This paper analyzes the $7 \mathrm{~s}$-20rice transport machine on soil compaction situation and studies its effects on soil parameters.

Firstly, The soil samples are placed in the two same cube containers in advance, and to measure its length $l$, width $w$ and height $h$.Then we need weigh the two soil samples, roller compacted soil quality $m_{1}$ as before, after crushing soil quality $m_{2}$. When data preparation is completed, we can use the formula to calculate soil samples of the soil firmness.

$$
\mu=\frac{F}{S}=\frac{m g}{S}
$$

$m$ is soil quality; ${ }^{g}$ is the acceleration of gravity; $S$ is the area.

And due to the confined area $S$ is set to the same value, and $g$ is constant, so the solid degree is proportional to the quality of the soil samples, namely:

$$
\mu=k \cdot m
$$

$k$ is the proportional coefficient.

And because the soil samples are in the same container, that is, their volumes are same.

By mass formula

$$
m=\rho \cdot v
$$

You can get, soil firmness is proportional to soil density, that is 


$$
\mu=k^{\prime} \cdot \rho
$$

$k^{\prime}$ is the proportional coefficient.

Through on-the-spot investigation, we got the $7 \mathrm{~s}-$ 20 rice transport machine mean specific pressure and the maximum pressure after the change of the solid data. That is table 4 and table 5 .

Table 4 the firmness variation after $7 \mathrm{~s}$ - 20 rice transfer machine (average pressure) presses

\begin{tabular}{|c|c|c|c|}
\hline depth & $\begin{array}{l}\text { The firmness } \\
\text { before press }\end{array}$ & $\begin{array}{l}\text { The firmness } \\
\text { after press }\end{array}$ & variation \\
\hline $\mathrm{cm}$ & $N / \mathrm{cm}^{3}$ & $N / \mathrm{cm}^{3}$ & $N / \mathrm{cm}^{3}$ \\
\hline 2 & 128 & 140 & 12 \\
\hline 6 & 138 & 149 & 11 \\
\hline 10 & 134 & 140 & 6 \\
\hline 14 & 132 & 136 & 4 \\
\hline 18 & 124 & 126 & 2 \\
\hline
\end{tabular}

Table 5 the firmness variation after $7 \mathrm{~s}-20$ rice transfer machine (maximum pressure) presses

\begin{tabular}{|c|c|c|c|}
\hline depth & $\begin{array}{l}\text { The firmness } \\
\text { before press }\end{array}$ & $\begin{array}{l}\text { The firmness } \\
\text { after press }\end{array}$ & variation \\
\hline $\mathrm{cm}$ & $\mathrm{N} / \mathrm{cm}^{3}$ & $\mathrm{~N} / \mathrm{cm}^{3}$ & $\mathrm{~N} / \mathrm{cm}^{3}$ \\
\hline 2 & 135 & 155 & 20 \\
\hline 6 & 143 & 158 & 15 \\
\hline 10 & 140 & 153 & 13 \\
\hline 14 & 136 & 146 & 10 \\
\hline 18 & 133 & 140 & 7 \\
\hline
\end{tabular}

For $7 \mathrm{~s}-20$ rice transfer machine, its increment is in slow decline, transfer machine in the 0 to $6 \mathrm{~cm}$ depth increased firmness 1.1 times and that of the original firmness $18 \mathrm{~cm}$ depth increase 1.05 times.

By the above conclusion, we can get the variation of soil density is small before and after $7 \mathrm{~s}-20$ crawler rice field transfer machine pressure. $7 \mathrm{~s}-20$ crawler rice field transfer machine does not affect the soil density.

\section{CONCLUSIONS}

$7 \mathrm{~s}-20$ rice field transfer machine is special processing machinery for shipment which aims at bagged rice placing in the field after the rice is harvested. In view of the actual situation, transfer machine is using a self-developed special gearbox; the machine has simple structure and convenient maintenance to facilitate the operator. At present, each link, such as rice seedlings, planting, harvesting, drying and so on, has a mature machinery and equipment at domestic. But only in the connection part of those links, such as soil seedling, seedling, rice, etc. does not have mature and reliable products. $7 \mathrm{~s}-20$ rice field transfer machine fills the gaps of mechanization.

\section{ACKNOWLEDGEMENT}

The authors here would like to express their gratitude for the sponsorship from China Spark Program (2012GA610010) and National College Students Practice and Innovation Training Project (201310060045).

\section{REFERENCES}

[1] Zheng Wenzhong, LiShun, zhou hong, Ren Yongye. Rice harvest mechanization technology popularization effect and its significance in communication discussion. Modern agricultural machinery, 2013, 1:5-7.

[2] Nanjing institute of agricultural mechanization the ministry of agriculture. The rice mechanization development trend during the period of "11th five-year plan" and suggesttion: hefei: 68-2005.

[3] Zhud e-feng, Chen hui-zhe, xu yicheng. The development prospect of the rice planting mechanization in our country and countermeasures. Journal of rice in the north, 2007, 5:13 to 18 .

[4] Zhang juan-li, shi ShuaiBing. Agricultural machinery operation on the experimental study of the influence of soil parameter. Journal of Chinese agricultural mechanization, 2011, 4:100-103. 